\title{
A comparative study of variations in arithmetic fluency between Norwegian and Finnish third graders
}

\section{Funderud, Tonje}

$2019-10-20$

pÿFunderud , T , Mononen , R , Radiai , J \& Laine , A 2019 , ' A comparative study of variations in arithmetic fluency between Norwegian and Finnish third graders ', European Journal of Special Needs Education, vol. 34 , no. 5 , pp. 572-585 . https://doi.org/10.1080/08856257.2018.1560618

http://hdl.handle.net/10138/316918

https://doi.org/10.1080/08856257.2018.1560618

unspecified

acceptedVersion

Downloaded from Helda, University of Helsinki institutional repository.

This is an electronic reprint of the original article.

This reprint may differ from the original in pagination and typographic detail.

Please cite the original version. 


\section{A Comparative Study of Variations in Arithmetic Fluency between}

\section{Norwegian and Finnish Third Graders}

Tonje Funderud $^{1)}$, Riikka Mononen ${ }^{1)}$, Jelena Radišićc ${ }^{2)}$ and Anu Laine ${ }^{3)}$

1) Department of Special Needs Education, University of Oslo, Norway

2) Department of Teacher Education and School Research, University of Oslo, Norway

3) Faculty of Educational Sciences, University of Helsinki, Finland

Correspondence concerning this article should be addressed to Riikka Mononen, Department of Special Needs Education, P.O. Box 1140, Blindern, 0318 Oslo, Norway. Email:

r.m.mononen@isp.uio.no. Tel: +47-22855638 


\section{A Comparative Study of Variations in Arithmetic Fluency between}

\section{Norwegian and Finnish Third Graders}

\section{Abstract}

The study aimed to investigate variations in addition and subtraction fluency by observing grade three students in Norway $\left(n=253, M_{a g e}=8.38\right.$ y.) and Finland $(n=$ $209, M_{\text {age }}=9.35 \mathrm{y}$.) while controlling for their age and non-verbal reasoning. Gender differences were also examined. The focus of the study was on the performance of the low-achieving (LA) students in comparison to the typically achieving (TA) group, not neglecting differences in how early educational support was organised across the two countries. Two-minute speed tests in both addition and subtraction within the 1-20 number range were used to assess fluency. The Finnish students outperformed students in the Norwegian sample both in addition and subtraction fluency. There were more Norwegian students in the LA group (i.e. performance at or below the $25^{\text {th }}$ percentile) in both addition (37.9\% vs. $20.1 \%)$ and subtraction (39.1\% vs. $15.8 \%)$. In comparison to the TA students, the LA students made more errors and skipped over more arithmetic tasks in an attempt to solve them. Observed differences are discussed in relation to both country characteristics concerning early mathematics education and early educational support.

Keywords: arithmetic fluency, arithmetic skills, comparative study, low achievers, third grade students 


\section{Introduction}

Numeracy skills, both independently and as part of general mathematical competence, are considered crucial to future employment in the modern labour market. At the same time, low academic achievement and learning difficulties (e.g., mathematical learning difficulties) are among the key predictors of school dropout (Hakkarainen, Holopainen, and Savolainen 2015; Korhonen, Linnanmäki, and Aunio 2014; Rumberger and Lim 2008). Estimates suggest that $5-7 \%$ of students have severe difficulties (i.e. developmental dyscalculia) in learning mathematics (2011), and if the low-achieving (LA) students are included, the number rises to 15-20\% (Geary 2011). Students having learning difficulties in mathematics are often characterized as having severe problems in basic arithmetic (Mazzocco, Devlin and McKenney 2008; Vanbinst, Ghesquière, and De Smedt 2014). While their peers are mostly fluent (i.e., accurate and fast) in solving basic arithmetic problems, these students rely on more immature and slower strategies, such as using their fingers as memory aids, and verbal counting. The difficulties in arithmetic fluency are usually identified around grade three (i.e., approximately at the age of nine), as this is the time when students following typical development start to be fluent in addition and subtraction especially within the number range from 0 to 20 (Aunio \& Räsänen 2016). Grade three students experiencing arithmetic fluency difficulties, in both Norway and Finland, are in the focus of this study.

In Norway, students begin with formal instruction in arithmetic at the age of six. In contrast, most six-year-olds in Finland are taking part in pre-primary education and start formal schooling at the age of seven. During this preparatory year, the children are introduced to different topics in mathematics mainly through playful activities, but no formal teaching in arithmetic is provided (Finnish National Board of Education [FNBE] 2016a). By the time they reach grade three, students in both countries will receive formal mathematics instruction for 
three school years. Notably, the Finnish pupils will be a year older than their Norwegian peers.

Another difference between the countries relates to the educational support system. In Finland, a three-tier model is followed, emphasising early support (Finnish National Agency for Education [FNAE] 2010), whereas, in Norway, students need to go through an external professional assessment concerning possible learning difficulties before they can receive any special educational support (Opplæringslova [Education law] 2005, §5-1).

Both these aspects represent an interesting starting point for the current investigation on arithmetic fluency in grade three students. More closely, the aim of this study is to investigate variations in addition and subtraction fluency of third graders in Norway and Finland, while controlling for their age and non-verbal reasoning. Gender differences are also observed.

Subsequently, departing from the existing differences in how early educational support differs between the countries, we will also examine (a) if there are differences in the proportion of LA students between the two countries, and (b) if there are differences in the patterns how the LA students solve the arithmetic tasks compared to their typically achieving (TA) peers.

\section{Individual Differences in Arithmetic Development}

In so far, some typical trajectories in the development of arithmetic skills have been identified. At the same time, individual differences have also been found following this development (Dowker 2009; Vanbinst, Ceulemans, Ghesquière, and De Smedt 2015). As research shows, arithmetic problems are typically solved using one of two basic approaches: retrieval strategies or backup strategies (Ostad 2013; Siegler and Jenkins 1989). Retrieval strategies are based on retrieving units from long-term memory, either as a whole unit $(6+6$ $=12)$ or as associations with a unit $(6+6=12$, so $6+7=$ one more, thus 13). Backup 
strategies, on the other hand, are based on using verbal counting to solve the problem, such as counting both addends (i.e. primary strategies) or counting up or down from any addend (i.e. more complex strategies) (Ostad 2013; Siegler and Jenkins 1989). Following the typical development trajectory, children start out using the primary backup strategies and gradually move on to more complex backup strategies, which include fewer counting steps, and move towards retrieval strategies. Simultaneously, they practice variation and flexibility in the use of strategies and start to adapt them to the task at hand (Dowker 2014; Ostad 1997, 1999; Siegler and Jenkins 1989). Canobi (2004) found that children in grades 1-3 were more fluent in solving addition than subtraction problems. Furthermore, counting on was the most used strategy in addition problems, whereas counting-up in subtraction. Thus, in this study we also treat addition and subtraction as separate components of arithmetic. As children get older, they use more advanced ways to solve arithmetic problems (Canobi, 2004). Around the age of nine, children typically begin to use fact retrieval as their primary strategy for addition and subtraction, and calculations within the number range 0-20 become fluent (Aunio and Räsänen 2015).

Although most children follow a typical development trajectory, some children struggle with learning arithmetic. Students with mathematical learning difficulties, and especially those with developmental dyscalculia (DD), are characterised by profound difficulties in the acquisition of various mathematical skills (Zhou and Cheng 2015), and deficits in basic arithmetic skills represent a distinct marker in these children (Vanbinst, Ghesquière, and De Smedt 2014; WHO 2018). Longitudinal studies (e.g. Dowker 2009; Ostad 1997, 1999) have found that children with difficulties in mathematics primarily make use of backup strategies based on counting, rather than retrieval strategies. Furthermore, children with mathematical learning difficulties seem to use the same strategies rigidly, with only minor variations, and 
with a limited degree of change or development of strategies through primary school (Dowker 2009; Ostad 1997, 1999). In their study, Jordan, Hanich and Kaplan (2003a) compared children with good and poor arithmetic fact mastery across the second and third grade. They found that general cognitive skills were a significant predictor of the use of finger counting to solve arithmetic tasks. Additionally, they showed that children with poor arithmetical fact mastery performed significantly lower on a measure of nonverbal abilities than the children with good arithmetic mastery. Furthermore, Vanbinst and colleagues (2015) found three different profiles of arithmetic development when observing grades three to five: 1) slow and variable, 2) average and 3) efficient, with a conclusion that symbolic numerical magnitude processing is an important factor in contributing to individual differences in arithmetic skills. They found no differences between the groups in digit naming, working memory or nonverbal reasoning. To conclude, the developmental trajectory of children with DD in arithmetic fact retrieval will most likely never catch up with that of TA children, but difficulties are rather persistent (Jordan et al. 2003a). However, LA children, although starting behind TA children, seem to exhibit better growth than children with DD, and their trajectory is rather similar to that of TA children, only delayed (Geary, Hoard, Nugent, and Bailey 2012; Ostad 1997, 1999).

\section{Gender Differences in Arithmetic}

Although there are studies that indicate no gender differences are observed in children's early mathematical skills (Kersey, Braham, Csumitta, Libertus, and Cantlon 2018), including first years of primary school (Hutchison, Lyons, and Ansari 2018), traditionally, the differences have been reported on. At the same time, the findings focusing on the differences remain inconsistent, seeking caution in interpretation. For example, it has been suggested that in later childhood girls perform better in basic arithmetic and boys in problem-solving (e.g. Carr and 
Alexeev 2011). Yet when comparing some of the studies focusing only on the array of arithmetic skills alone, the bulk of findings emerging from these are not aligned. For example in similar studies examining single- and multidigit number comparisons both gender differences favouring boys (Krinzinger, Wood, and Willmes 2012) and girls (Wei et al. 2012) have been reported.

Conversely, taking into account that any numerical processing is connected to different facets of ability with very different developmental trajectories (Lyons, Price, Vaessen, Blomert and Ansari 2014), some researchers have focused on the type of strategies boys and girls opt for when solving arithmetic problems (e.g. Bailey, Littlefield, and Geary 2012; Carr and Alexeev 2011). Such results indicate boys may be showing a preference for retrieval strategies earlier and to be solving addition tasks using retrieval more frequently and more quickly than the girls (Bailey et al. 2012). In addition to these, it seems that girls continue using manipulatives and counting fingers to solve basic arithmetic tasks for a longer period of time than the boys do (Carr and Alexeev 2011; Jordan, Hanich, and Kaplan 2003b).

\section{Mathematics education in early years of schooling in Norway and Finland}

The primary objective of the Norwegian and Finnish educational systems is to create equal opportunities for every child, regardless of the child's background, in order to equip every student with the basic skills needed to function in society (The Norwegian Directorate for Education and Training [UDIR] 2015a; Finnish National Board of Education [FNBE] 2016b). In respect to mathematics, this objective involves teaching children to use mathematical thinking and strategies to solve a variety of problems. Table 1 provides an overview of the content of mathematics instruction in both countries up to the second grade as portrayed in the national curricula (UDIR, 2013; FNBE 2016b). Whereas in Norway there are set competence aims to be reached at the end of the grade two, in Finland the content refers to those 
mathematical topics the instruction is to be given about. Nevertheless, the students are expected to get instruction and learn quite similar content regarding the number and operations. Students in both countries are expected to master basic arithmetic operations, namely addition and subtraction in the number range of 0-20 (UDIR 2013; FNBE 2016b). Neither of the countries provides specific learning aims for grade three mathematics, rather those are integrated with aims for other grades (e.g., in Norway competence aims to be reached by the end of grade 4, in Finland aims for grades 3-6). However, regarding arithmetic, during the third-grade children are expected to foster already learned content, widen number range and to learn algorithms. Regarding the pre-primary education year in Finland, which most of the children take part in, no formal arithmetic instruction is provided there, but children are introduced to different mathematics areas (i.e. verbal and object counting, and geometry) in hands-on activities and in a playful manner (FNBE 2016a).

\section{[Table 1 approximately here]}

In both countries, the learning conditions are quite similar. There are on average 16-17 students per classroom in the lower grades, and it is a common practice in both countries to have a teacher assistant present in the classroom if there are students in need of additional support. In both countries, students in the early grades receive around 3-4 hours of mathematics instruction, out of 20 in total, which is the weekly average (FNAE 2018; UDIR 2015b). Regarding teacher education, Finnish classroom teachers have a long history of having teacher education as a five-year master degree, whereas in Norway this has been taken into practice only in autumn 2017. Thus most of the Norwegian classroom teachers have a bachelor's degree in teacher education.

At the moment the major difference between the countries lies in the ways how educational support is organised. In Norway, children are entitled to receive special needs support only if 
they do not profit from regular instruction. Thus, the child can receive extra support based on external professional assessment, often conducted by an educational psychologist (Opplæringslova 2005, §5-1). In Finland, children who experience learning difficulties, or difficulties with other aspects of schooling, are entitled to educational support (FNAE 2010), which is based on a three-tier system: general support (Tier 1), intensified support (Tier 2) and special needs support (Tier 3). The provision of Tier 3 instruction is based on an extensive pedagogical assessment, supplemented by a psychological assessment (FNAE 2010). Currently, it seems that there is a better access to early support in the Finnish school system compared to the Norwegian one because in Finland the appropriate support can be started at Tier 1 and Tier 2 without external professional assessment. This is especially important regarding the early years of schooling when the emphasis is on early support.

\section{Research Questions and Hypotheses}

In the light of the previous investigations in the domain, the current study focuses on the following research questions:

RQ1: Are there differences in the arithmetic fluency (i.e. addition and subtraction) between Norwegian and Finnish grade three students, while controlling for age and non-verbal reasoning? We expect no performance differences between the countries in addition and subtraction fluency to be found, as students in both countries have been exposed to the equal number of years (i.e., three) in formal arithmetic instruction.

RQ2: Are there gender differences in the arithmetic fluency between and within countries? No gender differences are expected within and between the students in examined countries aligned with the findings of Kersey et al. (2018) and Hutchison et al. (2018). RQ3: Is there a difference in the proportion of LA students (i.e. performing at or below the $25^{\text {th }}$ percentile in addition or subtraction) between the two countries observed? 
Although we assume no performance differences between the country samples in general, we postulate that the proportion of LA students might differ, due to access to early support, based on the three-tier model, in mathematics instruction in Finland.

RQ4: Are there differences in the patterns of how the LA students solve the arithmetic tasks (i.e. number of attempts, skipping over tasks and incorrect answers) in comparison to the TA students (i.e. performing above the $25^{\text {th }}$ percentile in addition or subtraction) within and between the countries? Given the findings on delayed trajectory development of the LA children in comparison with their TA peers (e.g. Geary et al. 2012), it is expected that LA students will approach the arithmetic problems differently than the TA students. We postulate the LA students will be either slow and accurate or fast prompting many errors and/or skip problems, thus ending with a lower total score compared to their TA peers. No country differences are expected relative to how students approach the arithmetic problems.

\section{Method}

\section{Participants}

The current study is part of a larger project XXX (removed for peer review) focusing on thirdgrade students' mathematics learning and related motivation in four European countries. Here we focus only on the data gathered in Norway and Finland, from the capital regions of both countries. Schools were chosen to represent students with diverse socioeconomic status in both countries, and altogether data were collected from six schools in the Oslo area and four schools in Helsinki area. A total of 255 Norwegian and 215 Finnish third graders participated in the study. All students, with data on all the measures (i.e. arithmetic, non-verbal reasoning and age) were included in the final sample, that being 253 Norwegians (51.0\% boys) and 209 Finnish students ( $48.3 \%$ boys). The participants were on average 8.38 years old $(S D=0.48$ 
years) in Norway and 9.35 years old $(S D=0.52)$ and Finland. Consent forms for each child were collected from their parents.

\section{Measures}

Raven's Coloured Progressive Matrices

Raven's Coloured Progressive Matrices was used to assess the participants' nonverbal reasoning skills (Raven 1998). The children were given 36 tasks, two of which were practice items. One point was given for each correct answer, which resulted in a potential sum score of 34 points. The Cronbach's alphas for Raven's Matrices were 0.84 for the Norwegian sample and 0.88 for the Finnish sample.

Arithmetic Fluency Test

The Arithmetic Fluency Test (in Norwegian, Regnefaktaprøven, Klausen and Reikerås 2016) was used to measure arithmetic skills. This test is a Norwegian normed and standardised math test that assesses basic arithmetic skills in addition, subtraction, multiplication and division. In this study, the students completed the addition and subtraction subtests. Each subtest consists of 45 tasks for a single operation, within the number range of $0-20$. The children were asked to do as many tasks as possible, in a column-wise direction, within the timeframe of two minutes for each operation. One point was awarded for each correct answer; thus, the maximum score for each subtest was 45 points. The Cronbach's alphas for the Norwegian sample were 0.94 for the addition subtest and 0.92 for the subtraction subtest. For the Finnish sample, the Cronbach's alphas were 0.94 for the addition subtest and 0.93 for the subtraction subtest. Apart from the sub scores, analyses of the children's answering sheets on the Arithmetic Fluency Test were performed. A separate coding scheme was created to account 
for the direction (i.e. column- or row-wise) in which the child solved the tasks and how many tasks the child has left without an answer, together with the incorrect and skipped answers.

\section{Procedure}

The measures were administered in the spring of 2017 by trained research assistants in both countries. The children were informed about the study in advance, and instructions for each measure were given orally. With all the measures accounted for (i.e. even those not included in the present investigation), the testing lasted for a total of 1.5-2 hours, including a short break for the children. All measures were paper and pencil based.

\section{Data Analysis}

Since statistically significant difference was found in the students' performance on the Raven measure at a country level (see Results), Raven was included as a covariate in subsequent analyses. To compare the achievement between the countries in addition and subtraction fluency analyses of covariance (ANCOVAs) were performed, and besides non-verbal reasoning age was also used as a covariate. Following, gender differences were examined within and between the countries. The whole sample was then divided into two subgroups based on students' performance on the Arithmetic Fluency Test, separately for addition and subtraction: LA students (i.e. performing at or below the $25^{\text {th }}$ percentile, equals 15 points in addition and 12 points in subtraction) and TA students (i.e. performing above the $25^{\text {th }}$ percentile). The proportion of LA pupils between the countries was compared. Finally, the direction in which the tasks were answered, number of attempts, skipping over the tasks and incorrect answers were coded from the test protocols and descriptive data are provided for these. 


\section{Results}

The results on differences in nonverbal reasoning skills between the countries revealed that on average, third graders in Norway had statistically significantly higher scores on Raven's Coloured Matrices $(M=28.98, S D=4.23)$ than the Finnish third graders $(M=27.80, S D=$ $5.00), t(460)=2.73, p=.007, d=0.26$. Raven was therefore introduced as a covariate in the later analyses together with age.

\section{Addition and Subtraction Fluency}

A one-way ANCOVA was conducted to compare addition and subtraction skills between countries while controlling for non-verbal reasoning and age. The Finnish students outperformed those in Norway in both addition and subtraction. The country effect was small, explaining $4 \%$ of the variation in addition and $7 \%$ of the variation in subtraction performance (Table 2).

[Table 2 approximately here]

Regarding the gender differences, a one-way ANCOVA was conducted (controlling for nonverbal reasoning and age). A statistically significant difference between the Norwegian and Finnish boys both in addition and subtraction tasks was found, although the effect sizes were small ( $\eta=.03$ and $\eta=.06$, respectively). Similar results were found among the girls, with Finnish girls outperforming those in Norway $(\eta=.07$ in addition and $\eta=.11$ in subtraction).

When looking at the effect of gender on a country level, t-tests were conducted as there was no need to control for non-verbal reasoning and age. In Norway, boys outperformed the girls in addition (boys: $M=20.73, S D=9.39$, girls: $M=17.83, S D=7.73$ ), $t(251)=2.67, p=.008$, $d=0.34$, but not in subtraction (boys: $M=15.34, S D=7.17$, girls: $M=13.68, S D=6.41$ ), $t(251)=1.94, p=.053, d=0.24$. In the Finnish sample, there were no gender differences 
found in addition (boys: $M=24.99, S D=10.80$, girls: $M=23.40, S D=8.70), t(207)=1.18, p$ $=.241, d=0.16$, nor in subtraction (boys: $M=21.55, S D=9.57$, girls: $M=19.41, S D=$ $8.04), t(207)=1.76, p=.080, d=.24$.

Regarding the proportions of LA students, $37.9 \%(n=96)$ of students in the Norwegian sample were performing low in addition, in contrast to $20.1 \%(n=42)$ of the Finnish students. The proportion of LA students in subtraction mounted to $39.1 \%(n=99)$ in the Norwegian sample and $15.8 \%(n=33)$ in the Finnish sample.

\section{Attempts, Incorrect Answers, Skipping and Direction}

Tables 3 and 4 summarise the students' observed attempts (i.e. the final arithmetic problem recorded as completed in the test protocol) together with correct and incorrect answers and tasks skipped in addition and subtraction subtests, respectively.

[Table 3 approximately here]

When observing the addition tasks, all TA students succeeded in $93.7 \%$ of the attempted trials, whereas LA students were successful in $77.2 \%$ of the attempts. The LA students also skipped more tasks in their addition calculations compared to the TA students $(12.6 \% \mathrm{vs}$. 4.3\%). The most significant differences between the countries were found between the LA groups. Although the LA students in the Finnish sample attempted to solve more tasks, the percentage of correct answers was higher for the Norwegian sample $(86.3 \%)$, in contrast to $62.4 \%$ for the Finnish LA group. In other words, although the Finnish LA students worked through the addition tasks more quickly, they have made more errors and skipped over more tasks than their Norwegian LA peers.

[Table 4 approximately here] 
In subtraction, the TA students succeeded in $89.6 \%$ of the attempted trials, whereas LA students were successful only in $62.3 \%$ of the attempts. The LA students made almost five times more calculation errors compared to the TA students, and skipped more subtraction tasks. The Finnish LA students attempted more subtraction tasks than their Norwegian LA peers $(M=21.06$ vs. $M=10.53$, respectively), but that resulted in having more errors and skipping more of the subtraction tasks.

The Arithmetic Fluency Test instructs students to solve the arithmetic problems as accurately and as quickly as possible and to solve the tasks in a column-wise direction. The tasks themselves were presented in a random order rather than in order of increased difficulty. Since the students were instructed to calculate the tasks column-wise, the direction each student chose can, therefore, provide some insight into the students' capacity to follow instructions in general. Despite the instruction, a number of students solved the tasks following other than the column-wise direction. For example, a mix of the vertical and horizontal pattern was observed, as well as a row by row approach. Respectively, $4.8 \%$ of all the students solved the tasks using the row by row direction for addition and $1.9 \%$ students did the same in the subtraction subtest. More than one-fifth of the students exhibited a mixed pattern (22.8\% in addition and $20.8 \%$ in subtraction). The vast majority of the students followed the column-wise direction $(71.4 \%$ in addition and $77.3 \%$ in subtraction. The Norwegian students followed the instruction more often than the Finnish: $83.4 \%$ vs. $56.9 \%$ in addition and $88.5 \%$ vs. $63.6 \%$ in subtraction. Finally, in regards to the performance groups, LA students followed the instructions more closely than the TA students: $83.3 \%$ vs. $66.4 \%$ in addition, and $82.6 \%$ vs. $75.2 \%$ in subtraction.

\section{Discussion}


This study examined variations in arithmetic fluency between Norwegian and Finnish thirdgrade students. The main result of this study was that the Finnish third-graders outperformed their Norwegian peers, even when age and non-verbal reasoning were controlled for. Both Norwegian and Finnish third graders had received three years of formal mathematics education and based on their curricula, they were expected to have mastered basic addition and subtraction in the number range 1-20 (UDIR 2013; FNBE, 2016a). In both countries, third graders received a higher mean score on the addition subtest than on the subtraction subtest. This was expected since addition is the arithmetical operation children are introduced to first, it receives more attention during the initial years of schooling (Sarama and Clements 2009), and such a result has earlier emerged in the field (e.g. Canobi 2004).

The proportion of Norwegian students within the LA group was surprisingly higher compared to the Finnish sample. At the same time, the Finnish numbers are more aligned to the general estimations of students performing at a lower level in mathematics (15-20\%, Geary 2011). Although not directly observed, we can postulate that such results do mirror different educational support systems existing in the two countries and that the three-tier support system in Finland does possibly a better job in identifying students that require support in the early years. The hypothesis is yet to be tested, but currently some strong grounds for investigating this further may be found in the study published by the Children's Commissioner in Norway (Barneombudet 2017), where a clear argument is put that many students in Norway that do receive special needs education do not get the provisions to which they are entitled to, while both the teachers and the teacher assistants implementing the instruction usually lack relevant accreditations.

Observing possible gender differences was an important aspect of this study. Both girls and boys in the Finnish sample were better than those in Norway, although the effect sizes were 
small $(\eta=.03-.11)$. Within the countries, no gender differences were found for the Finnish sample, similar to prior research of Kersey et al. (2018) and Hutchison et al. (2018). However, boys in Norway outperformed the girls in addition fluency. This result was rather observed from the perspective of possible different developmental trajectories as proposed by Lyons et al. (2014) and the prior results suggesting boys utilise fact retrieval earlier and more frequently than the girls (Bailey et al. 2012), as well as that the girls would use immature arithmetic strategies for a longer period of time than the boys (Carr and Alexeev 2011; Jordan, Hanich, and Kaplan 2003b). At the same time why Norwegian boys were better than girls only in addition fluency, but not in subtraction requires further investigation, by observing more directly at the arithmetic strategies (e.g. backup strategies, fingers etc.) students utilise while solving the tasks like the one used in this study, and taking into consideration other cognitive factors that might explain the performance differences, such as phonological processing and working memory (Vanbinst et al. 2015).

Focusing on how students had approached the arithmetic tasks, we found that in comparing the TA and the LA students, the former answered correctly to more tasks than the latter (between $89-94 \%$ and $62-77 \%$, respectively) when observing the total amount of recorded attempts in the answering sheets. Furthermore, particular differences were also found between the Norwegian and the Finnish LA group. The students in the Norwegian sample had solved fewer tasks in total, but with more accuracy. The LA student in Finland, on the other hand, made more attempts, resulting in more errors and skipping of the tasks in each of the subtests. Based on that, we can postulate that these two groups have had different approaches to solving arithmetic tasks in a timed situation. The Finnish students have tried to solve as many tasks as possible, or have tried to find the easiest ones among the total number of tasks introduced in the subtests by skipping particular test items, and/or without taking sufficient 
time to use the strategies they might have had acquired as part of formal instruction. The performance of Norwegian LA students, on the other hand, indicates relying on primary backup strategies with rather longer response time (Carr and Alexeev 2011), given both a low number of total attempts and the correct answers. In future studies, a computerized adaptive arithmetic test might be used in order to capture with more precision the type of task students accurately perform on (Martin and Lazendic 2018).

\section{Future Research and Educational Implications}

This comparative study utilised a cross-sectional design. The results indicated a significant difference between the arithmetic fluency of third graders in Norway and Finland, favouring the latter. When conducting comparative studies between countries of different educational systems, there is always a number of issues to take into consideration. In this study, we controlled for age and cognitive ability, due to differences in the age of starting the formal arithmetic instruction, as well as found differences in non-verbal reasoning. Although there was found a statistically significant mean difference between the groups in Raven $(M$ difference 1.17$)$, the effect size was small $(d=0.26)$. In order to trying to find an explanation for what might be the reasons for this difference, favouring a year younger children, more detailed background information about the participants would have been needed. Differences in organizing the educational support in both countries, and the curricula provisions in the early years of schooling were taken into account, but not directly observed. These issues are to be taken into account in the follow-up study, in order not only to capture more precise information on the students' cognitive and math abilities but also to pick up on in more detail on the learning opportunities the students are provided for within the two systems. In addition to this, capturing students' performance in three consecutive years (i.e. grades 1 to 3 ) may contribute to findings on possible diverse developmental trajectories and strategy choices between boys and girls and the TA and LA students, allowing for a more targeted support. 
Finally, from the perspective of direct implications, the current study has, the importance of teaching and learning arithmetic skills should be underlined. Arithmetic skills are not limited to merely remembering facts. To be fluent in arithmetic skills, the child needs to have a broad knowledge of arithmetic operations and of how numbers and operations are related to each other. Children with strong arithmetic knowledge are more likely to use complex strategies and fact retrieval effectively later on. Moreover, fluency in arithmetic facts is an important foundation for future mathematical skills (Carr and Alexeev 2011; Kilpatrick, Swafford, and Findell 2001; Sarama and Clements 2009), thus understanding its particular developmental trajectories and differences across different subgroups is of at most importance.

\section{Acknowledgments}

We wish to thank all participating schools, teachers and students in Norway and Finland, and we gratefully acknowledge the research assistants' contribution to the data collection.

\section{Disclosure statement}

No potential conflict of interest was reported by the authors.

\section{References}

Aunio, P., and P. Räsänen. 2016. “Core Numerical Skills for Learning Mathematics in Children Aged Five to Eight Years - A Working Model for Educators.” European Early Childhood Education Research Journal 24: 684-704. doi: 10.1080/1350293X.2014.996424.

Bailey, D. H., A. Littlefield, and D. C. Geary. 2012. "The Codevelopment of Skill at and Preference for Use of Retrieval-Based Processes for Solving Addition Problems: Individual and Sex Differences from First to Sixth Grades.” Journal of Experimental Child Psychology 113: 78-92. doi: 10.1016/j.jecp.2012.04.014. 
Barneombudet. 2017. Uten Mål og Mening? Elever medSspesialundervisning i Skolen [Without Aims and Meaning? Students with Special Educational Needs at School]. http://barneombudet.no/wp-content/uploads/2017/03/Bo_rapport_enkeltsider.pdf.

Canobi, K. H. 2004. “Individual Differences in Children's Addition and Subtraction Knowledge.” Cognitive Development 19 (1): 81-93. doi: 10.1016/j.cogdev.2003.10.001

Carr, M., and N. Alexeev. 2011. "Fluency, Accuracy, and Gender Predict Developmental Trajectories of Arithmetic Strategies." Journal of Educational Psychology 103 (3): 617-631. doi: 10.1037/a0023864.

Dowker, A. 2009. "Use of Derived Fact Strategies by Children with Mathematical Difficulties." Cognitive Development 24: 401-410. doi: 10.1016/j.cogdev.2009.09.005.

Dowker, A. 2014. "Young Children's Use of Derived Fact Strategies for Addition and Subtraction." Frontiers in Human Neuroscience 7 (924): 1-9. doi: 10.3389/fnhum.2013.00924.

Finnish National Board of Education (FNBE). 2016a. National Core Curriculum for PrePrimary Education 2014. Finnish National Board of Education. Porvoo, Finland: Porvoon Kirjakeskus Oy.

Finnish National Board of Education (FNBE). 2016b. National Core Curriculum for Basic Education 2014. Finnish National Board of Education. Porvoo, Finland: Porvoon Kirjakeskus Oy.

Finnish National Agency for Education (FNAE). 2010. Basic Education Act. http://www.finlex.fi/en/laki/kaannokset/1998/en19980628.pdf.

Finnish National Agency for Education (FNAE). 2018. Education in Finland. Accessed May 12, 2018. http://oph.fi/download/175015_education_in_Finland.pdf. 
Geary, D. C. 2011. "Consequences, Characteristics, and Causes of Mathematical Learning Disabilities and Persistent Low Achievement in Mathematics.” Journal of Developmental \& Behavioral Pediatrics 32: 250-263.

Geary, D. C., M. K. Hoard, L. Nugent, and D. H. Bailey. 2012. "Mathematical Cognition Deficits in Children with Learning Disabilities and Persistent Low Achievement: A Five-Year Prospective Study.” Journal of Educational Psychology 104 (1): 206-223. doi: $10.1037 / \mathrm{a} 0025398$.

Hakkarainen, A. M., L. K. Holopainen, and H. K. Savolainen. 2015. “A Five-Year Follow-Up on the Role of Educational Support in Preventing Dropout from Upper Secondary Education in Finland.” Journal of Learning Disabilities 48(4): 408-421. doi: 10.1177/0022219413507603.

Hutchison, J. E., I. M. Lyons, and D. Ansari. 2018. "More Similar Than Different: Gender Differences in Children's Basic Numerical Skills Are the Exception Not the Rule.” Child Development. Advance online publication: doi: https://doi.org/10.1111/cdev.13044.

Jordan, N. C., L. B. Hanich, and D. Kaplan. 2003a. “A Longitudinal Study of Mathematical Competencies in Children with Specific Mathematics Difficulties versus Children with Comorbid Mathematics and Reading Difficulties." Child Development 74 (3): 834850. doi: 10.1111/1467-8624.00571.

Jordan, N. C., L. B. Hanich, and D. Kaplan. 2003b. “Arithmetic Fact Mastery in Young Children: A Longitudinal Investigation.” Experimental Child Psychology 85: 103-119. doi: 10.1016/S0022-0965(03)00032-8.

Kersey, A. J., E. J. Braham, K. D. Csumitta, M. E. Libertus, and J. F. Cantlon. 2018.” No Intrinsic Gender Differences in Children's Earliest Numerical Abilities.” NPJ Science of Learning 3 (12). doi:10.1038/s41539-018-0028-7. 
Kilpatrick, J., J. Swafford, and B. Findell. 2001. Adding It Up: Helping Children Learn Mathematics. Washington, DC: National Academy Press.

Klausen, T., and E. Reikerås. 2016. Regnefaktaprøven [The Arithmetic Fluency Test]. Stavanger: Lesesenteret, Universitetet i Stavanger.

Korhonen, J., K. Linnanmäki, and P. Aunio. 2014. "Learning Difficulties, Academic WellBeing and Educational Dropout: A Person-Centred Approach.” Learning and Individual Differences 31: 1-10. doi: 10.1016/j.lindif.2013.12.011.

Krinzinger, H., G. Wood, and K. Willmes. 2012. "What Accounts for Individual and Gender Differences in the Multi-Digit Number Processing of Primary School Children?" Zeitschrift für Psychologie. 220: 78-89. doi: 10.1027/2151-2604/a000099.

Lyons, I. M., G. R. Price, A. Vaessen, L. Blomert, and D. Ansari. 2014. "Numerical predictors of arithmetic success in grades 1-6.” Developmental Science 17 (5): 714 726. doi: $10.1111 /$ desc. 12152 .

Martin, A. J., and G. Lazendic. 2018. “Computer-adaptive testing: Implications for students' achievement, motivation, engagement, and subjective test experience. " Journal of Educational Psychology 110 (1): 27-45. http://dx.doi.org/10.1037/edu0000205.

Mazzocco, M. M. M., K. T. Devlin, and S. J. McKenney. 2008. "Is It a Fact? Timed Arithmetic Performance of Children With Mathematical Learning Disabilities (MLD) Varies as a Function of How MLD Is Defined.” Developmental Neuropsychology 33 (3): 318-344. doi: 10.1080/87565640801982403.

Opplæringslova. [Education law] Lov 17. juni 2005 nr. 5-1 om Rett til Spesialundervisning [Law $17^{\text {th }}$ June no. 5-1 about the Right for Special Needs Education].

Ostad, S. A. 1997. "Developmental Differences in Addition Strategies: A Comparison of Mathematically Disabled and Mathematically Normal Children.” British Journal of Educational Psychology 67: 345-357. doi: 10.1111/j.2044-8279.1997.tb01249.x. 
Ostad, S. A. 1999. "Developmental Progression of Subtraction Strategies: A Comparison of Mathematically Normal and Mathematically Disabled Children." European Journal of Special Needs Education 14 (1): 21-36. doi: 10.1080/0885625990140103.

Ostad, S. A. 2013. Strategier, Strategiobservasjon og Strategiopploering: Fokus på Elever med Matematikkvansker [Strategies, Strategy Observation and Strategy Learning: Focus on Students with Mathematical Learning Difficulties]. Trondheim: Læreboka forlag.

Raven, J. C. 1998. Raven's Progressive Matrices. Oxford: Oxford Psychologists Press.

Rumberger, R. W., and S. A. Lim. 2008. "Why Students Drop Out of School: A Review of 25 Years of Research.” California Dropout Research Project Report \#15.

Sarama, J., and D. H. Clements. 2009. Early Childhood Mathematics Education Research: Learning Trajectories for Young Children. New York: Routledge.

Siegler, R. S., and E. Jenkins. 1989. How Children Discover New Strategies. Hillsdale: Lawrence Erlbaum Associates, Inc.

UDIR. 2013. Laereplan i Matematikk Fellesfag (MAT01-04) [Learning Plan in Mathematics]. Accessed August 1, 2018. https://www.udir.no/k106/mat1-04

UDIR. 2015a. Generell Del av Loereplanen [General Part of the Learning Plan]. Accessed August 1, 2018. https://www.udir.no/laring-og-trivsel/lareplanverket/generell-del-avlareplanen/innleiing/pdf.

UDIR. 2015b. Utdanningsspeilet: tall og analyse av barnehager og grunnopplaeringen $i$ Norge [Educational Mirror: Number and Analysis of Kindergarten and Basic Education in Norway]. https://www.udir.no/globalassets/filer/tall-ogforskning/rapporter/utdanningsspeilet_2015.pdf. 
Vanbinst, K., E. Ceulemans, P. Ghesquière, and B. De Smedt. 2015. "Profiles of Children's Arithmetic Fact Development: a Model-Based Clustering Approach." Journal of Experimental Child Psychology 133: 29-46. doi: 10.1016/j.jecp.2015.01.003.

Vanbinst, K., P. Ghesquière, and B. De Smedt. 2014. “Arithmetic Strategy Development and Its Domain-Specific and Domain-General Cognitive Correlates: A Longitudinal Study in Children with Persistent Mathematical Learning Difficulties." Research in Developmental Disabilities 35: 3001-3013. doi: 10.1016/j.ridd.2014.06.023.

Wei, W., H. Lu, H. Zhao, C. Chen, Q. Dong, and X. Zhou. 2012. "Gender Differences in Children's Arithmetic Performance Are Accounted for by Gender Differences in Language Abilities.” Psychological Science 23 (3): 320-330. doi: $10.1177 / 0956797611427168$.

WHO. 2018. The 11th Revision of the International Classification of Diseases (ICD-11). https://icd.who.int/browse11/1-m/en

Zhou, X., and D. Cheng. 2015. "When and Why Numerosity Processing Is Associated with Developmental Dyscalculia.” In The Routledge International Handbook of Dyscalculia and Mathematical Learning Difficulties, edited by S. Chinn, 78-89. Abingdon: Routledge. 
Table 1. Content of mathematics instruction, namely Numbers, in early grades (1-2) in Norway and Finland based on the national curricula (UDIR 2013; FNBE 2016b)

Content Country

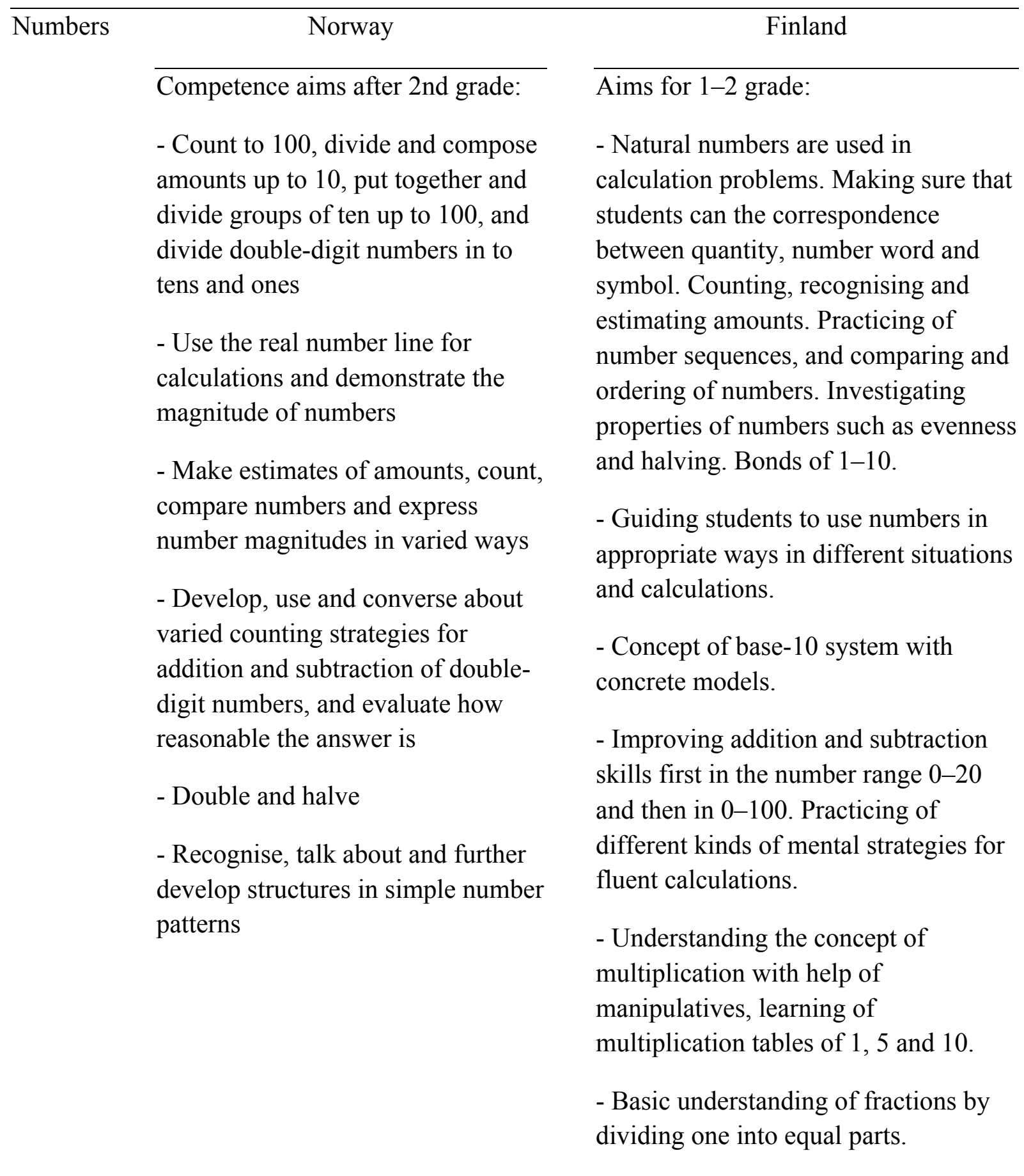


Table 2. Performance in addition and subtraction tasks by country and gender.

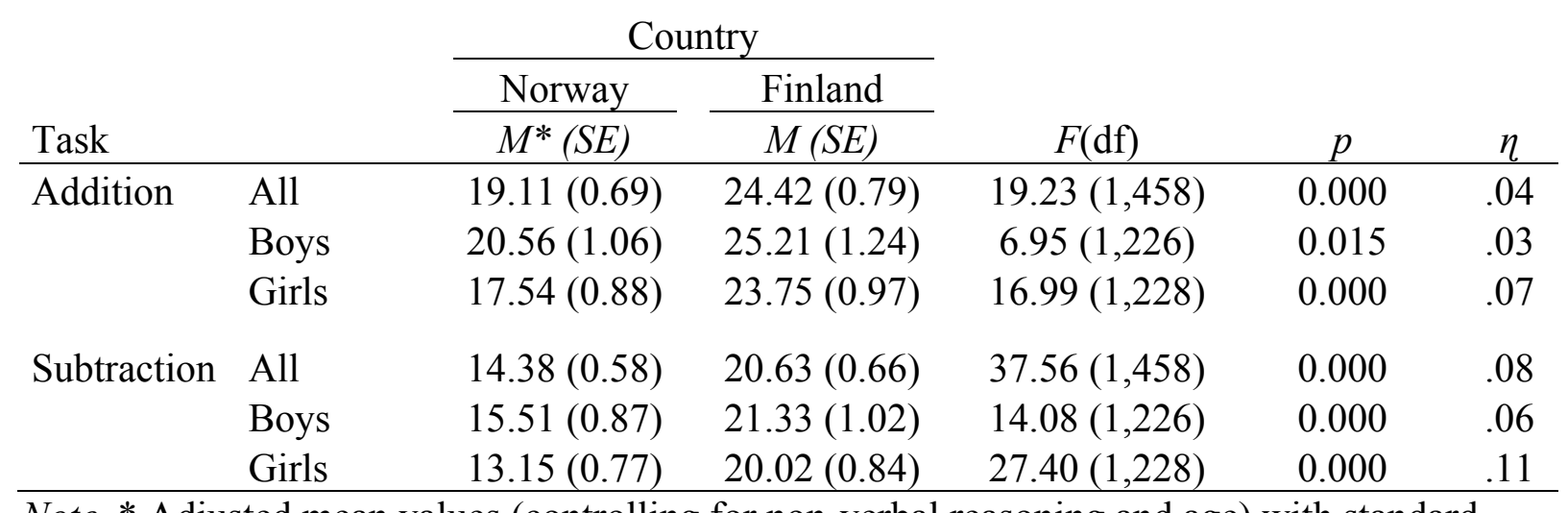

Note. * Adjusted mean values (controlling for non-verbal reasoning and age) with standard errors are reported. 
Table 3. Descriptive statistics for attempts, correct and incorrect answers and skipping in addition subtest

\begin{tabular}{lllcccc}
\hline Sample & Group & $N$ & Attempts* & Correct* & Incorrect* & Skipping* \\
\hline All & TA & 324 & 27.62 & 25.87 & 0.58 & 1.19 \\
& & & & $(93.7 \%)$ & $(2.1 \%)$ & $(4.3 \%)$ \\
& LA & \multirow{2}{*}{138} & 14.58 & $\begin{array}{c}11.26 \\
(77.2 \%)\end{array}$ & $\begin{array}{c}1.90 \\
(13.0 \%)\end{array}$ & $\begin{array}{c}1.42 \\
\end{array}$ \\
& & & & 24.27 & 0.61 & 1.17 \\
\hline Norway & TA & 157 & 26.04 & $(93.2 \%)$ & $(2.3 \%)$ & $(4.5 \%)$ \\
& & & & 11.21 & 0.75 & 1.03 \\
& LA & \multirow{2}{*}{96} & 12.99 & $(86.3 \%)$ & $(5.8 \%)$ & $(7.9 \%)$ \\
\hline Finland & TA & \multirow{2}{*}{167} & 29.10 & 27.38 & 0.54 & 1.20 \\
& & & & $(94.1 \%)$ & $(1.9 \%)$ & $(4.1 \%)$ \\
& \multirow{2}{*}{42} & 18.21 & 11.39 & 4.52 & 2.31 \\
& & & & $(62.4 \%)$ & $(24.8 \%)$ & $(12.7 \%)$ \\
\hline
\end{tabular}

Note. Percentages calculated in relation to total attempts. *mean values 
Table 4. Descriptive statistics for attempts, correct and incorrect answers and skipping in subtraction subtest

\begin{tabular}{lllcccc}
\hline Sample & Group & $N$ & Attempts* & Correct* & Incorrect* & Skipping* \\
\hline All & TA & 330 & 23.22 & 20.80 & 0.95 & 1.47 \\
& & & & $(89.6 \%)$ & $(4.1 \%)$ & $(6.3 \%)$ \\
& LA & \multirow{2}{*}{132} & \multirow{2}{*}{13.16} & 8.20 & 2.50 & 2.45 \\
& & & & $(62.3 \%)$ & $(19.0 \%)$ & $(18.6 \%)$ \\
\hline Norway & TA & \multirow{2}{*}{154} & 21.21 & 18.54 & 0.82 & 0.85 \\
& & & & $(87.4 \%)$ & $(3.9 \%)$ & $(4.0 \%)$ \\
& LA & \multirow{2}{*}{99} & \multirow{2}{*}{10.53} & 8.28 & 1.20 & 1.04 \\
& & & & $(78.6 \%)$ & $(11.4 \%)$ & $(9.9 \%)$ \\
\hline Finland & TA & \multirow{2}{*}{176} & 25.84 & 22.78 & 1.07 & 2.01 \\
& & & & $(88.2 \%)$ & $(4.1 \%)$ & $(7.8 \%)$ \\
& LA & \multirow{2}{*}{33} & 21.06 & 7.97 & 6.39 & 6.70 \\
& & & & $(37.8 \%)$ & $(30.3 \%)$ & $(31.8 \%)$ \\
\hline
\end{tabular}

Note. Percentages calculated in relation to total attempts. *mean values 